Classification

Physics Abstracts

81.05.Je - 81.70.Yp - 07.05.Pj

\title{
Morphological Study during a Ceramic Process
}

\author{
Michel Coster $\left({ }^{1}\right)$, Muriel Prod'homme $\left({ }^{2}\right)$, Liliane Chermant $\left({ }^{1}\right)$ \\ and Jean-Louis Chermant $\left({ }^{1}\right)$ \\ ( $\left.{ }^{1}\right)$ LERMAT, URA CNRS 1317, ISMRA, 6 bd Maréchal Juin, 14050 Caen Cedex, France \\ $\left({ }^{2}\right)$ Thomson LCC, Avenue du Colonel Prat, 21850 St Appollinaire, France
}

\begin{abstract}
Résumé. - L'analyse d'images est un outil très bien adapté pour suivre un procédé de fabrication industriel dans lequel les propriétés du produit final dépendent de la morphologie du matériau. Dans cet article, on présente l'étude et le suivi morphologique durant la fabrication de condensateurs céramiques à base de titanate de barium. Les trois étapes principales du procédé sont étudiées par trois méthodes morphologiques différentes. Un certain nombre de relations entre la morphologie et les propriétés physiques du matériau diélectrique a été établie.
\end{abstract}

\begin{abstract}
Image analysis is a very well adapted tool to follow an industrial process where the properties of final products depend on material morphology. In this paper, the case of morphological study during the process of baryum titanate ceramic capacitors is presented. Three main stages of this process are studied by three different morphological methods. Many relationships between morphological and physical properties of dielectric material have been established.
\end{abstract}

\section{Introduction}

The main dielectric material used in ceramic capacitors is baryum titanate $\left(\mathrm{BaTiO}_{3}\right)$. The three different stages of the process which have been investigated by automatic image analysis correspond to three states of materials: powder, green films and sintered products. Although the role of the morphology is very important for the quality of ceramic capacitors, very few works have been published in this domain [1]. In this paper, a synthetic presentation of the Prod'homme work's [2] is given. It allows to understand the role of the morphology on physical characteristics of ceramic capacitors [3]. These capacitors are obtained according to a classical process. The green film of $50 \mu \mathrm{m}$ thickness is obtained from a mixture of baryum titanate powder, binder and plasticizer after evaporation of the solvents. After screen printing process, these films are stacked and sintered to obtain blocks of capacitors.

The morphology of these process stages are very different. This is the reason why the morphological tools must be adapted to each state. 


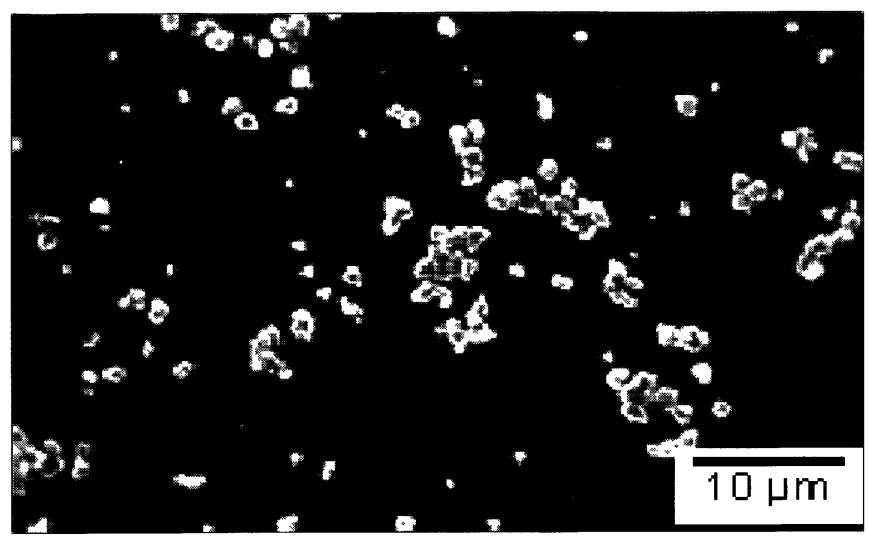

Fig. 1. - Scanning Electron microscope image of $\mathrm{BaTiO}_{3}$ powder.

Table I. - Topological characteristics of powder aggregates.

\begin{tabular}{|c|c|c|c|c|}
\hline Units per & \multicolumn{2}{|c|}{ Powder 1 } & \multicolumn{2}{c|}{ Powder 2 } \\
\cline { 2 - 5 } aggregate & mean & $\begin{array}{c}\text { standard } \\
\text { deviation }\end{array}$ & mean & $\begin{array}{c}\text { standard } \\
\text { deviation }\end{array}$ \\
\hline minima & 6.4 & 6.6 & 3.9 & 4.5 \\
maxima & 12.5 & 12.4 & 8.16 & 7.7 \\
minima/maxima & $51 \%$ & & $48 \%$ & \\
\hline h-minima = 16 & 2.02 & 2.01 & 1.20 & 0.48 \\
h-maxima = 16 & 3.28 & 3.2 & 2.62 & 2.3 \\
h-minima/h-maxima & $62 \%$ & & $46 \%$ & \\
\hline
\end{tabular}

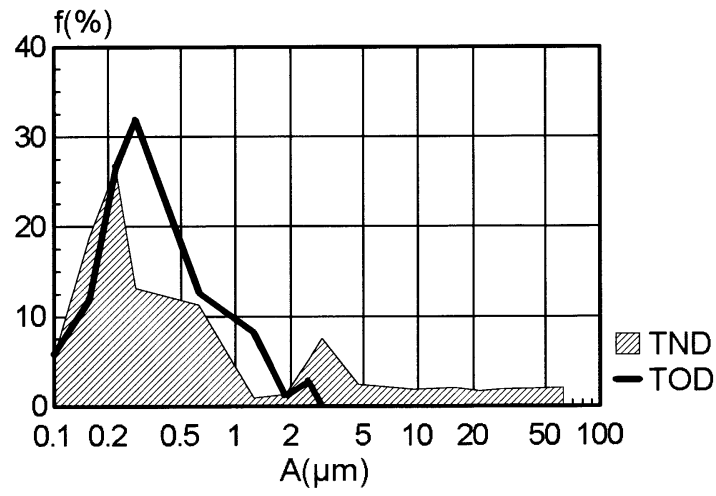

Fig. 2.

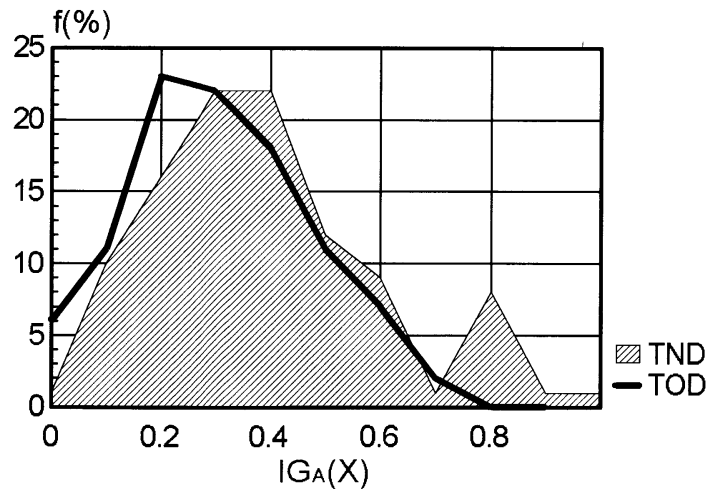

Fig. 3.

Fig. 2. - Size distribution (area) for non dispersed (TND) and dispersed (TOD) powaers.

Fig. 3. - Histogram of shape distribution for TND and TOD powders according to geodesic lengthening indice. 


\section{Morphological Study of the Powder}

The physical behaviour of powder materials depends mainly on the size and the shape of aggregates. To estimate these morphological characteristics, the $\mathrm{BaTiO}_{3}$ powder is dispersed on the polished top of a brass cylinder. The scanning electron microscope (SEM) images in backscattered electron mode (Fig. 1) are analysed by different methods.

Granulometric Analysis. - The SEM grey level image is thresholded. In this condition the size measurement is performed on the projection of aggregates or grains (projected image). The chosen parameters are the area, $A(\mathrm{X})$, the geodesic length, $\mathrm{Lg}(\mathrm{X})$, the maximum and minimum Feret diameter, $\left(F_{\max }(\mathrm{X}), F_{\min }(\mathrm{X})\right)$, and the thickness, $\mathrm{De}(\mathrm{X})$. To obtain the size distribution, the individual analysis method is used with the Lantuejoul frame correction [4]. Figure 2 exhibits the difference between the size distribution with and without dispersing agent. In this last case, the distribution presents two modes and is coarser.

Shape AnAlysis. - Two methods were used to characterize the aggregate shape. The first one is relatively classical since it was performed from shape indice measurements on projected images. Several shape indices were tested. The better parameters were chosen after data and correlation analysis. The geodesic lengthening indice is given by the following equation [5]:

$$
\mathrm{IG}_{\mathrm{a}}(\mathrm{A})=1-\frac{4 \times A(\mathrm{X})}{\pi \times \mathrm{Lg}^{2}(\mathrm{X})}
$$

This indice which has been also defined by Lantuéjoul and Toniolo [6] appears to be one of the best. Figure 3 exhibits the influence of dispersing agent on the granulomorphic distribution [3] obtained with this parameter.

To distinguish the two types of powder used, this classical method is not powerful. In a recent work, Mathis and Coster [7] have used the texture analysis of SEM grey tone images to perform this analysis. After showing that surface roughness on aggregates of the two $\mathrm{BaTiO}_{3}$ powders are approximately the same, Mathis [8] proposed to choose the numbers of $h$ maxima and $h$ minima per aggregate which are better than the numbers of maxima or minima themselves because these parameters are less sensitive to the noise (Tab. I), (see also [9]).
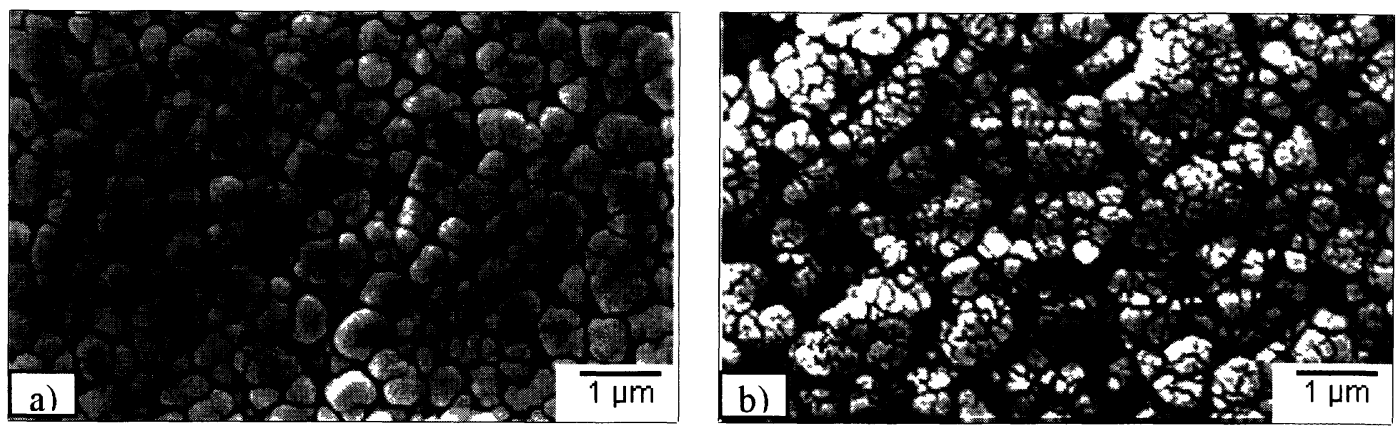

Fig. 4. - Scanning electron micrographs of two different ( $a$ and $b$ ) textures of green films. 
a)

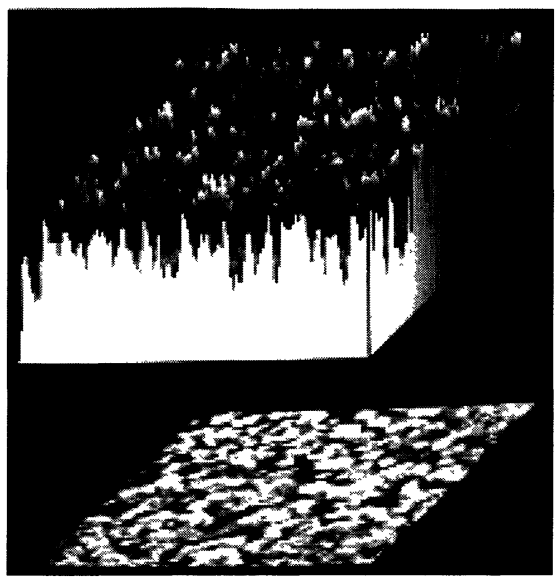

b)

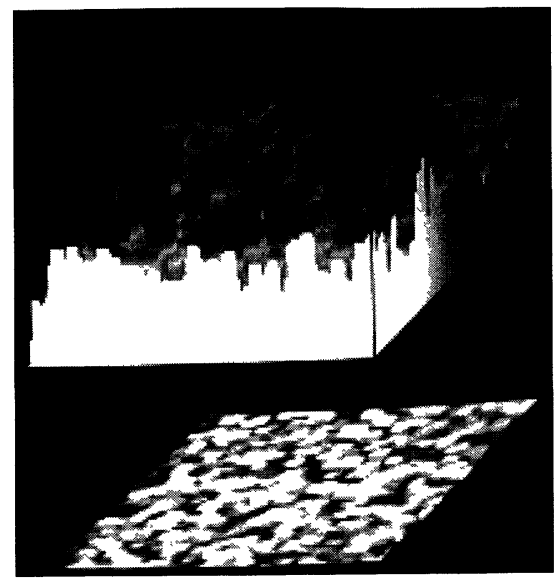

Fig. 5. - Grey level images of $\mathrm{BaTiO}_{3}$ film: a) initial image and after an opening by a square structuring element of 11 pixels $b$ ).

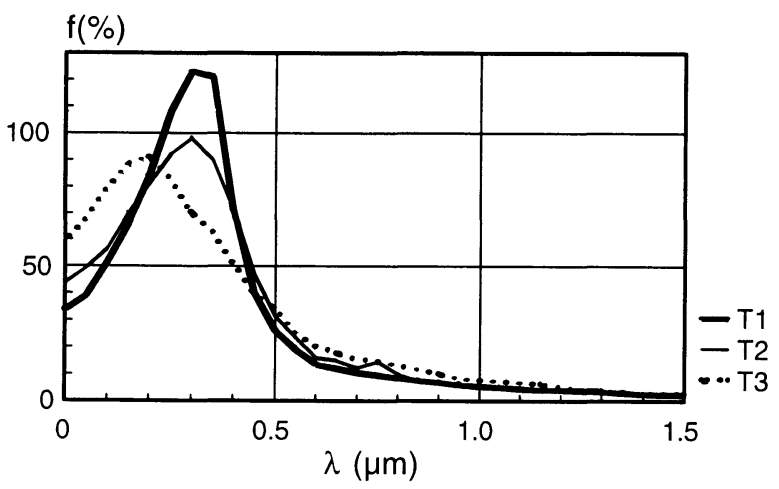

Fig. 6. - Granulometric distribution by opening from 3 different textures.

\section{Morphological Study of Green Film}

Figures $4 \mathrm{a}$ and $4 \mathrm{~b}$ show the surface texture of green film obtained by SEM for two milling conditions. After preliminary studies, the granulometric analysis of these grey tone images by flat structuring element was performed [10] to obtain the size distribution according to the relationship:

$$
G(f, \lambda)=\frac{\int f(x) \mathrm{d} x-\int O^{\lambda \mathrm{B}}(f(x)) \mathrm{d} x}{\int f(x) \mathrm{d} x} .
$$

One must measure the volume of the initial image $f(x)$ and opened image $O^{\lambda \mathrm{B}}(f(x))$ which is illustrated respectively in Figures 5a and 5b. Figure 6 exhibits the influence of milling conditions on the texture granulometry of green films. 


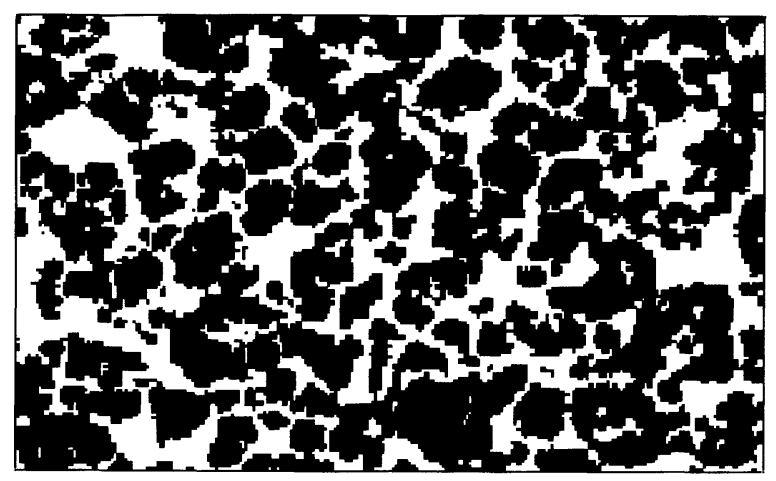

Fig. 7. - Automatic threshold on texture by method of maximization of entropy.

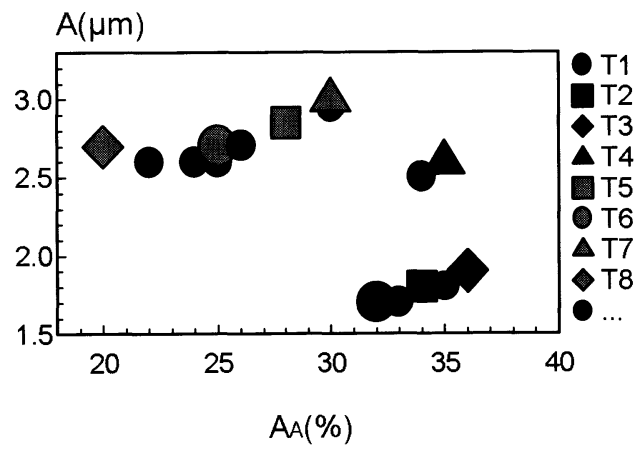

Fig. 8. - Correlation study between $A_{\mathrm{A}}(\mathrm{P})$ and $\bar{A}(\mathrm{P})$.

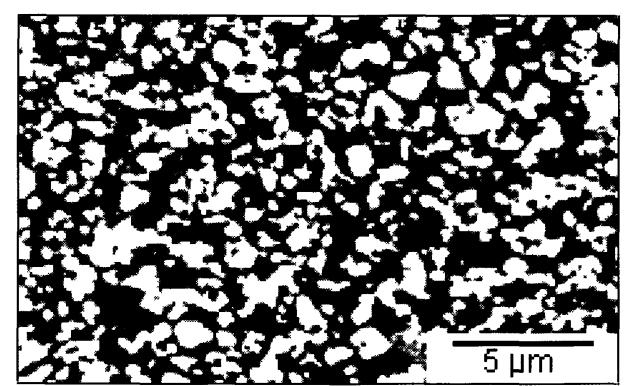

a)

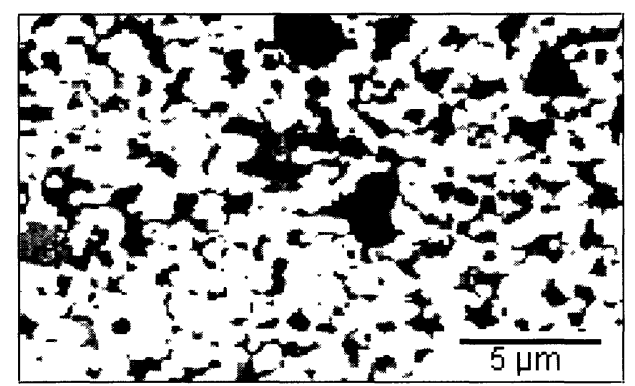

b)

Fig. 9. - Scanning electron micrographs of sintered materials at $850^{\circ} \mathrm{C} \mathrm{(a)}$ and $1150^{\circ} \mathrm{C}$ (b).

To characterize the porous network of the green film, an automatic threshold was chosen. Several methods were tested. The best one (Fig. 7) is that given by the two following image transformations:

- automedian filter with flat structuring element of four pixels to eliminate the noise and defined by the following equation:

$$
\beta(f(x))=\sup \left(F^{\mathrm{B}} O^{\mathrm{B}} F(f(x)) ; \inf \left(O^{\mathrm{B}} F^{\mathrm{B}} O^{\mathrm{B}}(f(x)) ; f(x)\right)\right) ;
$$

- threshold by entropy maximization [11]. 


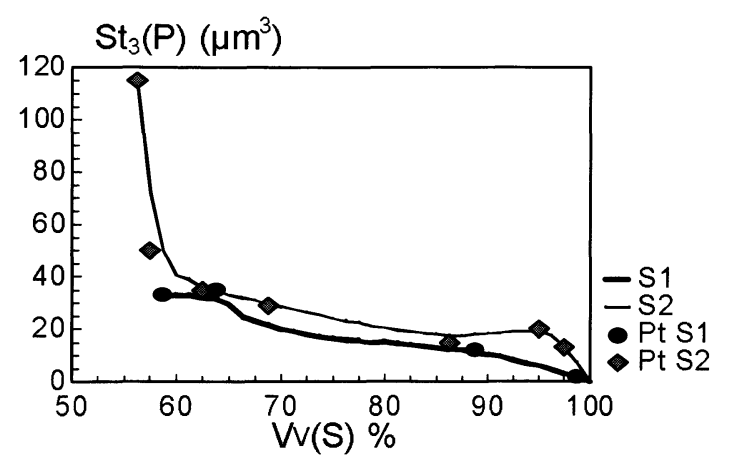

Fig. 10. - Evolution of the 3D star of pores as a function of the volumic fraction of material.

Then, the binary image is analysed by the classical stereological parameters on porous phase $\mathrm{P}$ : surface area, $A_{\mathrm{A}}(\mathrm{P})$, specific perimeter, $L_{\mathrm{A}}(\mathrm{P})$, specific connectivity number, $N_{\mathrm{A}}(\mathrm{P})$, and the mean size of the opening distribution of pores, $\bar{A}(\mathrm{P})$. No very simple correlation exists between $A_{\mathrm{A}}(\mathrm{P})$ and $\bar{A}(\mathrm{P})$ when milling conditions change (textures T1,T2,T3) (Fig. 8).

\section{Sintering Process Study}

Figures $9 \mathrm{a}$ and $9 \mathrm{~b}$ exhibit the morphology of two sintered steps with the same milling conditions. The sintering steps have been analysed from stereological parameters in the porous phase: specific surface area, $S_{\mathrm{v}}(\mathrm{P})$, mean length, $L_{1}(\mathrm{P})$, integer of mean curvature, $M_{\mathrm{v}}(\mathrm{P})$, and star function in $\mathbb{R}^{3}, \mathrm{St}_{3}(\mathrm{P})$, determined from the $P(\ell)$ function $[12,13]$ performed on thresholded images of polished sections. Figure 10, corresponding to the evolution of the star function with the porosity, exhibits a different behaviour when milling conditions change (samples $S_{1}$ and $S_{2}$ ). In the case of $\mathrm{S}_{2}$ sample (Fig. 10) the strongly decreasing value of $\mathrm{St}_{3}(\mathrm{P})$ corresponds to the closure of channels between agglomerates.

\section{Conclusion}

In this paper, only morphological methods were presented. These morphological analyses are a good complement to understand the influence of processes on characteristics of final product. The works of Prod'homme [2] has allowed an increasing quality for this industrial product.

\section{Acknowledgements}

This work has been performed in the frame of the "Pôle Traitement et Analyse d'Images, TAI, de Basse Normandie", and the support of the Groupement Scientifique "De la Poudre aux Composants" from MRES and Thomson-LCC, St Appolinaire.

\section{References}

[1] Karas A., Kumagal T. and Cannon R.W., Adv. Ceram. Mat. 3 (1988) 374.

[2] Prod'homme M., Approche morphologique et physique d'un diélectrique pour condensateur multicouche : de la poudre au fritté, Thèse de Doctorat de l'Université de Caen (1992). 
[3] Prod'homme M., Chermant L., Chermant J.L. and Coster M., Acta Stereol. 13 (1994) 369.

[4] Lantuéjoul C., Microsc. Acta S4 (1980) 256.

[5] Chermant J.L. and Coster M., École "Minéraux finements divisés" organised by SFMC, ANRT and Les Ciments Français (Mantes la Jolie, France, 29-31 Janv 1992) Sci. Geol. Bull. 46 (1993) 45.

[6] Lantuéjoul C. and Toniolo G., 8th annual Meeting of the French Group of the International Society for Stereology (Paris, 7 Feb. 1985).

[7] Mathis S. and Coster M., Acta Stereol. 14 (1996) 201.

[8] Mathis S., Acquisition et analyse quantitative des images de microreliefs en microscopie confocale et en microscopie électronique à balayage, Thèse de Doctorat de l'Université de Caen (1996).

[9] Coster M., Gauthier G. and Chermant J.L., Roughness an funçtion analysis: methods and applications in material sciences, Microsc. Microanal. Microstructr. 7 (1996) 533.

[10] Prod'homme M., Coster M, Chermant L. and Chermant J.L., Scan. Microsc. 6 (1992) 255.

[11] Zeboudj R., Filtrage, seuillage automatique, contraste et contours: du pré-traitement à l'analyse d'image, Thèse de Doctorat de l'Université de Saint Etienne (1988).

[12] Coster M. and Chermant J.L., Précis d'Analyse d'Images, 2nd Ed. (Les Presses du CNRS, Paris 1989).

[13] Serra J., Image Analysis and Mathematical Morphology (Academic Press, London, 1982). 